\title{
The longitudinal relations among dimensions of parenting styles, sympathy, prosocial moral reasoning, and prosocial behaviors
}

\author{
Gustavo Carlo,' Maria Vicenta Mestre, ${ }^{2}$ Paula Samper, ${ }^{2}$ \\ Ana Tur, ${ }^{2}$ and Brian E. Armenta'
}

\begin{abstract}
Developmental scholars assert that parents are important in fostering prosocial behaviors in adolescents, but longitudinal investigations on this topic are limited. Participants consisted of 372 boys and 358 girls with a mean age of I0.84 years (SD = I.57) at Wave I from a mostly middle class community in Spain. Across three successive years, participants completed measures of fathers' and mothers' warmth and strict control, sympathy, prosocial moral reasoning, and self- and peer-reported prosocial behaviors. Results showed that parental warmth, sympathy, and prosocial moral reasoning were predictive of prosocial behaviors. Further analyses showed bidirectional effects such that early prosocial behaviors predicted later parenting and adolescents' prosociality. Findings lend support to cognitive-developmental and moral internalization models of prosocial development.
\end{abstract}

\section{Keywords}

moral reasoning, parenting, prosocial behaviors, sympathy

According to socialization theorists (Bandura, 1986; Hoffman, 2000; Staub, 1979), parents play an important role in promoting and fostering prosocial behaviors in their children and adolescents. Prosocial behaviors have been defined as actions primarily intended to benefit others (Eisenberg, Fabes, \& Spinrad, 2006). Sharing and donating resources, comforting others, volunteering for charitable activities, and helping needy others are typical forms of prosocial behaviors and most parents around the world desire their youth to exhibit such behaviors. Despite the importance accorded to such actions, research on the relations between parenting and prosocial behaviors in adolescence is limited (e.g., lack of longitudinal studies), and there is sparse research on these relations in youth from countries other than the United States (Carlo, 2006; Eisenberg $\&$ Valiente, 2002). Moreover, the associations among parenting and individual level variables (e.g., prosocial moral reasoning, i.e., thoughts regarding helping opportunities where one's own needs are in conflict with those of another in the relative absence of formal laws or social guidelines; sympathy, i.e., feelings of concern or sorrow) and prosocial behaviors are not well understood. Thus, longitudinal research on these links in youth from other countries could substantially further our understanding of prosocial development.

\section{Relations between parenting and prosocial behaviors}

Developmental scholars have accumulated a relatively large knowledge base regarding two major dimensions of parenting styles: warmth (or support) and control (or demandingness) (Barber, Stolz, \& Olsen, 2005; Baumrind, 1991; Maccoby \&
Martin, 1983). Parental warmth can be defined as the presence of positive affect, responsiveness, and support in parent-child relationships. Parental control, in contrast, refers to the degree of strictness, behavioral rules, and expectations imposed on children by parents. Warm parent-child relationships, which are conceptually related to secure attachment relationships, are hypothesized to facilitate emotional sensitivity, perspective taking (i.e., awareness and understanding other people's situations), and prosocial behaviors (Barnett, 1987; De Wolff \& van IJzendoorn, 1997). In contrast, the conceptual links between parental control and prosocial behaviors is somewhat more complex and depends upon the harshness and rigidity of control. For example, parents who are overly strict and controlling might place undue demands on children, which might lead to negative affect (e.g., anger), and more self-focused thoughts and actions (Rollins \& Thomas, 1979). Furthermore, parental control mixed with harsh verbal and physical disciplining practices might lead to aggressive and antisocial behaviors (Eisenberg \& Valiente, 2002; Hoffman, 2000; Maccoby \& Martin, 1983). Thus, a warm and supportive parent is viewed as an important resource associated with positive developmental outcomes, whereas overly controlling parents, in general, are associated with negative developmental outcomes.

\footnotetext{
' University of Nebraska-Lincoln, United States

${ }^{2}$ University of Valencia, Spain
}

Corresponding author:

Gustavo Carlo, University of Nebraska-Lincoln-Psychology, 320 Burnett Hall, Lincoln, NE 68588, USA.

E-mail: gcarlol@unl.edu 
Researchers have shown relatively consistent positive associations between responsiveness and prosocial behaviors in adolescence (Dekovic \& Jaansens, 1992; Eberly \& Montemayor, 1998; Lawford, Pratt, Hunsberger, \& Pancer, 2005; Mestre, Samper, Nácher, Tur, \& Cortés, 2006). To a lesser extent, there is also supportive evidence for the negative link between parental overcontrol and prosocial behaviors (see Eisenberg et al., 2006). However, the longitudinal evidence on the links between parenting styles and prosocial behaviors is limited, especially among adolescents (Carlo, 2006). Furthermore, one might expect that by adolescence, because of the push for autonomy and identity formation (Erikson, 1968), youth might respond differently to parents who are supportive or overly controlling. Moreover, studies of these relations that examine warmth and control in both fathers and mothers are scarce.

\section{Relations among parenting, sympathy, prosocial moral reasoning, and prosocial behaviors}

Social cognitive theorists speculate that warm parenting fosters and models empathy (i.e., feeling the same as another) and sympathy (Eisenberg, 1986; Staub, 1979). Furthermore, specific parenting styles might also facilitate higher levels and other-oriented forms of prosocial moral reasoning through perspective taking (i.e., understanding others' situations), sympathy, or directly by encouraging consideration of others (Eisenberg, 1986). In contrast, overly strict and punitive parenting might mitigate such other-oriented, prosocial traits (Hoffman, 2000).

A few investigators have shown that the general dimensions of parenting styles are associated with sympathy and prohibitive moral reasoning (i.e., moral dilemmas regarding breaking formal laws or social rules; see Hoffman, 2000) but studies focusing directly on prosocial moral reasoning are sparse. In general, parental warmth should be related positively to sympathy and prosocial moral reasoning, whereas parental control (especially overly strict control) should be related negatively or nonsignificantly to such traits (Carlo, 2006; Eisenberg et al., 2006; see Pratt, Skoe, \& Arnold, 2004). In contrast, there is substantial prior evidence that empathy and sympathy are linked positively to prosocial behaviors, including altruistic behaviors (Carlo, Hausmann, Christiansen, \& Randall, 2003; Eisenberg, Zhou, \& Koller, 2001; see Eisenberg \& Miller, 1987). There are also several findings that are consistent with the notion that prosocial moral reasoning is positively related to both sympathy and prosocial behaviors (Carlo et al., 2003; Eisenberg et al., 1999, 2001). However, in most studies, the indirect effects of parenting styles on prosocial behaviors via the contributions of sympathy and prosocial moral reasoning have been inferred via cross-sectional, rather than longitudinal, study designs.

\section{Possible bidirectional effects between variables}

Finally, scholars have noted the need to investigate possible bidirectional effects in studies of parenting and youth variables (Bell, 1968; Maccoby \& Martin, 1983). With regard to prosocial development, Carlo and Randall (2001) proposed that there might be feedback effects on prosocial traits in youth such that those who engage in prosocial behaviors might experience social feedback (e.g., rewards) that promotes moral reasoning and sympathy development (cf. Eisenberg, 1986). In one study, early prosocial actions predicted later prosocial traits and behaviors in adolescence (Eisenberg et al., 1999). Moreover, one might expect that parents would respond more favorably to youth who exhibit high levels of prosocial behaviors. Thus, youth prosocial behaviors might predict more warmth and less control from parents. To further explore this issue, we examined whether prosocial behaviors in early adolescence were associated with prosocial traits and parenting in later adolescence.

\section{Studies of prosocial development in European youth}

Studies of prosocial development in youth from European countries are also relatively scarce (see Carlo, 2006; Eisenberg et al., 2006, for reviews). The present study was conducted to examine prosocial development in adolescents from Spain. Similar to other Hispanic cultures, Spain is generally characterized as a society that values the family and religion as major and central social institutions (Centro de Investigaciones Sociológicas, 2004; Samper, 1999). Moreover, in general, Spain ranks somewhat higher on individualism, and somewhat lower in masculinity, than other Latino cultures, such as Venezuela, Mexico, Colombia, Argentina, and Brazil (Hofstede, 2001). However, Spain is substantially lower on individualism than the US and is towards the middle as compared to other industrialized countries (Hofstede, 2001). Therefore, Spain is considered a moderately collectivist, feminine-oriented society (FernándezBerrocal, Salovey, Vera, Ramos, \& Extremera, 2001). These general characteristics are undoubtedly changing as Spain experiences population and economic growth (de Prada, Actis, \& Pereda, 2005), especially since joining the European Union. Additionally, it is important to acknowledge the wide variations on these dimensions across individuals and groups within Spain. Given the prior research that demonstrates that family connections, collectivistic values and religiousness are associated with prosocial tendencies (Carlo, 2006), the general orientation of Spanish society provides an opportunity to examine the role of parents on youth prosocial development in a somewhat different sample than those in most prior studies.

\section{Summary of hypotheses}

Based on theory and prior research, we expected that parental warmth would be positively associated with sympathy, prosocial moral reasoning, and prosocial behaviors; whereas we expected parental control to be negatively linked to those prosocial tendencies. We also hypothesized that both sympathy and prosocial moral reasoning would be positively related to prosocial behaviors and that sympathy would be positively related to prosocial moral reasoning. These effects were expected concurrently as well as longitudinally (over three successive years). Based on theory (Bell, 1968), we also explored whether prosocial behaviors in early adolescence are associated with prosocial traits and parenting in later adolescence. Based on prior reported age and gender differences in adolescents' prosocial tendencies (Eisenberg et al., 2006) such that girls and older youth score higher on these measures, we explored whether the models fit equally well across older and younger adolescents and boys and girls. 


\section{Method}

\section{Participants}

Nine hundred and eighty-eight Spanish-speaking, early adolescents were originally recruited to participate in a three-wave longitudinal study in Valencia, Spain, examining parenting styles, sympathy, prosocial moral reasoning, and prosocial behaviors. Seven hundred and thirty adolescents fully completed surveys at all three waves. Thus, the final sample consisted of 372 boys (51\%) and 358 girls $(49 \%)$ with a mean age of 10.84 years $(S D=1.57$; Range $=$ 9-14). Three hundred and forty five $(47 \%)$ were primary school children $(475 \%$ girls; $53 \%$ boys; $M$ age $=9.24$ years, $S D=.43$ ) and $385(53 \%)$ were secondary school children ( $51 \%$ girls; $49 \%$ boys; $M$ age $=12.26$ years, $S D=.47$ ). To calculate socioeconomic status (SES), the Hollingshead classification scheme (adapted for Spain) was used (Ibáñez, 2005). The scale ranges from 1 to 7 ( $1=$ top level administrative and business executives; $3=$ mid-level administrators including administrative secretaries, insurance agents; $5=$ skilled manual laborers such as auto mechanics, carpenters; $7=$ unskilled workers such as cleaning workers, porters). The mean SES was $3.11(S D=1.23$; Primary children $M=2.96, S D=1.24$; Secondary children $M=3.25, S D=1.20$ ).

The schools that participated were randomly selected from the total schools in Valencia, Spain, that had students enrolled in the fourth level of Primary Education and the first level of Secondary Obligatory Education (SEO). The schools were predominantly from industrial zones, rural zones, and zones in transition from rural to industrial zones. Valencia has five small municipalities of between approximately 1,200 to 5,500 inhabitants. The rest of the municipalities have approximate populations between 30,000 and 60,000 except for the capital municipality, which has approximately 807,000 inhabitants (Instituto Nacional de Estadistica, 2008, http://www.ine.es/).

\section{Procedure}

In total, 22 schools (out of approximately 100 possible schools) participated, including 67 classrooms (31 Primary Education and 36 SEO). Appropriate institutional review board (IRB) approval from the School Council and informed parental consent were obtained and participation by students was voluntary. The survey packet was administered by trained research staff to groups of students in two 45-minute sessions in their classrooms during school hours. The annual assessments occurred for three successive years during the first quarter of the school course.

\section{Measures}

All of the following instruments were previously translated into Spanish by a moral developmental researcher from Spain who is fluent in Spanish, and back translated by a fellow, bilingual researcher, and they have been used in prior studies of adolescents from Spain. All measures were youth self-report except for a one-item peer report measure of prosocial behavior.

Parental warmth and strict control were assessed with mother and father warmth (positive evaluation, expression of affection, emotional support) and strict control (intrusiveness, strong parental direction, and control) subscales of the Child's Report of Parent Behavior Inventory (Samper, Cortés, Mestre, Nácher, \& Tur, 2006; Schaefer, 1965). Participants indicated the degree to which several family situations applied to them on a 3-point scale $(1=$ total agreement, 2 = situation sometimes applies, $3=$ totally different). Sample items include "Almost always speaks to me in a warm and friendly voice" (warmth; eight items) and "Wants to control everything I do" (strict control; six items after dropping two items due to low loadings). The scales showed adequate alphas at each wave (mother warmth: $\alpha \mathrm{s}=.70, .76, .75$, respectively; mother strict control: $\alpha \mathrm{s}=.61, .62, .61$, respectively; father warmth: $\alpha \mathrm{s}=.79$, $.81, .79$, respectively; father strict control: $\alpha \mathrm{s}=.63, .65, .61$, respectively). This measure was previously adapted and validated for use with Spanish adolescents (Mestre et al., 2006; Samper, 1999; Samper et al., 2006).

Sympathy was assessed using the 22-item Index of Empathy for Children and Adolescents (IECA; Bryant, 1982; Mestre, Pérez Delgado, Frías, \& Samper, 1999). Although the measure was originally conceptualized as empathy, the measure more closely assesses sympathy (sample items, "It's hard for me to see when someone else gets upset" [reverse coded]) (see Eisenberg \& Miller, 1987, for a critique). Children indicated their emotional sensitivity to others who are in distress and in need of help using a dichotomous no/yes response scale. Scores were created by averaging across the items. These items showed adequate internal consistency across all three waves $(\alpha \mathrm{s}=.70, .73, .74$, respectively). Prior research demonstrates adequate reliability and validity for this measure (e.g., Mestre, Frias, Samper, \& Tur, 2002; Mestre et al., 1999).

Prosocial moral reasoning was assessed with the Prosocial Reasoning Objective Measure (PROM; Carlo, Eisenberg, \& Knight, 1992). The PROM contains seven stories designed to invoke a conflict between the actor's needs, wants, and desires and those of others. Due to time limitations for the primary school children, only three stories were used. The three stories included depict situations about (a) helping a peer who is being teased versus incurring rejection from peers, (b) donating blood to a needy other at the cost of losing money at work and school, and (c) going to the beach with friends or helping a peer study for a math exam. A sample story is as follows:

Sandy (Begoña) was a student at school. One day Sandy was walking into her new class early and saw an older girl teasing and making fun of another girl's clothes. The girl was crying. There was no one else around and Sandy did not know the girls very well, but she had heard that the girl that was being teased was very poor and the older girl had a lot of friends. Sandy thought that maybe she should try to stop the older girl but she was afraid that the older girl and her friends might pick on her and tease her also.

For each story, youth indicated whether the protagonist should or should not help and then indicated the importance of five different reasons (on a 5-point scale, anchored by $1=$ not at all and 5 = greatly). The reasons reflect Eisenberg's (1986) empirically supported theoretical perspective, which suggests that prosocial moral reasoning undergoes a developmental progression from childhood through adolescence. Thus, in the order of progression from less to more mature forms of moral reasoning, each story included reasons reflecting hedonistic moral reasoning (e.g., "it depends whether Sandy can find other friends to do things with in school"), needs-oriented moral reasoning (e.g., "it depends whether the other girl is crying a lot"), approval-oriented moral reasoning (e.g., “it depends whether Sandy's classmates would approve of what she does"), stereotyped moral reasoning (e.g., "it depends whether Sandy thinks the older girl is mean or not"), and internalized moral reasoning (e.g., "it depends whether Sandy thinks that she is doing what she believes she should do"). 
Table I. Mean comparisons across waves (standard deviations in parentheses)

\begin{tabular}{|c|c|c|c|c|c|}
\hline & Wave I & Wave 2 & Wave 3 & $F(2,1864)$ & $\eta^{2}$ \\
\hline \multirow[t]{2}{*}{ Mother warmth } & 2.50 & 2.51 & 2.48 & 1.71 & $<.01$ \\
\hline & $(.32)$ & $(.33)$ & $(.33)$ & & \\
\hline \multirow[t]{2}{*}{ Father warmth } & $2.44^{\mathrm{b}}$ & $2.44^{\mathrm{b}}$ & $2.37^{\mathrm{a}}$ & $13.27 * *$ & .02 \\
\hline & $(.39)$ & $(.38)$ & $(.38)$ & & \\
\hline \multirow[t]{2}{*}{ Mother strict control } & $2.02^{c}$ & $1.89^{\mathrm{b}}$ & $1.8 \mathrm{I}^{\mathrm{a}}$ & 72.11 ** & .09 \\
\hline & $(.40)$ & $(.39)$ & $(.37)$ & & \\
\hline \multirow[t]{2}{*}{ Father strict control } & $1.91^{c}$ & $1.78^{b}$ & $1.74^{\mathrm{a}}$ & $55.34 * *$ & .07 \\
\hline & $(.4 I)$ & $(.40)$ & $(.38)$ & & \\
\hline \multirow[t]{2}{*}{ Sympathy } & $.68^{\mathrm{a}}$ & $.71^{\mathrm{b}}$ & $.72^{c}$ & $21.09 * *$ & .03 \\
\hline & $(.16)$ & $(.16)$ & $(.16)$ & & \\
\hline \multirow[t]{2}{*}{ Moral reasoning } & $1.85^{\mathrm{a}}$ & $1.86^{b}$ & $1.86^{a b}$ & $4.02 *$ & .01 \\
\hline & $(.07)$ & $(.08)$ & $(.07)$ & & \\
\hline \multicolumn{6}{|l|}{ Prosocial behavior } \\
\hline \multirow[t]{2}{*}{ Child report } & $2.53^{\mathrm{a}}$ & $2.56^{\mathrm{b}}$ & $2.54^{\mathrm{a}}$ & $5.06 * *$ & .01 \\
\hline & $(.28)$ & $(.28)$ & $(.28)$ & & \\
\hline \multirow[t]{2}{*}{ Peer report } & $4.85^{\mathrm{b}}$ & $4.73^{\mathrm{a}}$ & $4.90^{b}$ & $15.44 * *$ & .02 \\
\hline & $(.84)$ & $(.93)$ & $(.86)$ & & \\
\hline
\end{tabular}

Note. Values with different superscript letters are significantly different. Apparent small differences in means in sympathy and prosocial moral reasoning are deceiving because the scores are proportion scores (for prosocial moral reasoning) and the range of scores is quite limited. $* *_{p}<.01 ; *_{p}<.05$.

Scale scores were calculated through four-stage process (as described in prior research; Carlo et al., 1992). First, scale scores for each type of prosocial moral reasoning were derived by averaging across each type of item from the three stories. Second, because all adolescents are expected to engage in each type of moral reasoning but show greater preference for some over others, proportion scores were computed by dividing each scale score by the sum total of responses to all five scale scores. Third, because the five types of prosocial moral reasoning reflect varying levels of development, weights were applied to the proportion scores; hedonistic and needs- oriented were weighted by 1 , approval-oriented and stereotypic were weighted by 2 , and internalized was weighted by 3 . Finally, composite prosocial moral reasoning scores were computed by summing across the weighted proportion scores. This composite score (15 item scale) has a theoretical range from 1.43 (total preference for hedonistic moral reasoning) to 5.31 (total preference for internalized moral reasoning). The final composite scores showed adequate internal consistency for each wave ( $\alpha \mathrm{s}=$ $.67, .69, .72$, respectively). The PROM also has demonstrated acceptable reliability (including confirmatory factor analyses), construct, convergent, and discriminant validity with adolescents, including research with adolescents from Spain (Carlo, Koller, Eisenberg, Da Silva, \& Frohlich, 1996; Carlo, McGinley, Roesch, \& Kaminski, 2008; Mestre et al., 2002).

Prosocial behavior was measured in two ways. First, peer-reports of each student's prosocial behavior were assessed using a one item of generosity. Students were asked to rate each classmate on how generous they are providing examples (e.g., sharing food or a pen, donating money for a drink) on a 7 -point scale $(1=$ never, $4=$ sometimes, 7 = almost always). Second, adolescents' self-rated prosocial behaviors (sample item, "I help my classmates do their homework") on a 3 -point scale (options $1=$ never, 2 = sometimes, $3=$ always) using the 10 item prosocial subscale of the Prosocial Behavior Scale (Caprara \& Pastorelli, 1993; Del Barrio, Moreno, \& López, 2001; Mestre et al., 2006). This measure showed adequate alphas across the three waves $(.71, .74, .75$, respectively). Scores were summed and averaged.

\section{Results}

\section{Preliminary missing data analyses, descriptive statistics, and correlational analyses}

Youth with complete data were higher in socioeconomic status $(M=3.49, S D=1.21)$ than their counterparts without full data $(M=3.11, S D=1.23), F(1,986)=17.93, p<.001$. There were no other significant differences. Based on these findings, the results reported are based on adolescents with complete data and SES was controlled in the main analyses. Means, standard deviations, and repeated measure analysis of variances (ANOVAs) to examine mean differences at each wave for each variable are reported in Table 1.

\section{Analytic strategy}

A series of structural equation models were examined using maximum likelihood estimation and the Mplus 3.01 software program. For each model, observed scale and item scores were included, and child- and peer-reported prosocial behaviors served as indicators of a single latent prosocial behavior variable. For these models, paths were included from warmth and strict control to sympathy, prosocial moral reasoning, and prosocial behaviors; from sympathy to prosocial moral reasoning and prosocial behaviors; and from prosocial moral reasoning to prosocial behaviors. Separate models were tested for the mothers' and fathers' parenting variables. Preliminary models were estimated to examine the associations within each wave separately. The longitudinal model was then tested in using the parenting variables at Wave 1, sympathy and prosocial moral reasoning at Wave 2, and prosocial behaviors at Wave 3. Wave 1 sympathy, prosocial moral reasoning, and prosocial behaviors were included as controls for their corresponding Wave 2 and 3 counterparts. Models were determined to fit the data well if they produced values of CFI $>.95$, RMSEA $<.06$, and SRMR $<.08$ ( Hu \& Bentler, 1999).

Age group and gender were next examined as moderators of the longitudinal associations using multiple group analyses. A four 
1a. Mother warmth and strict control.

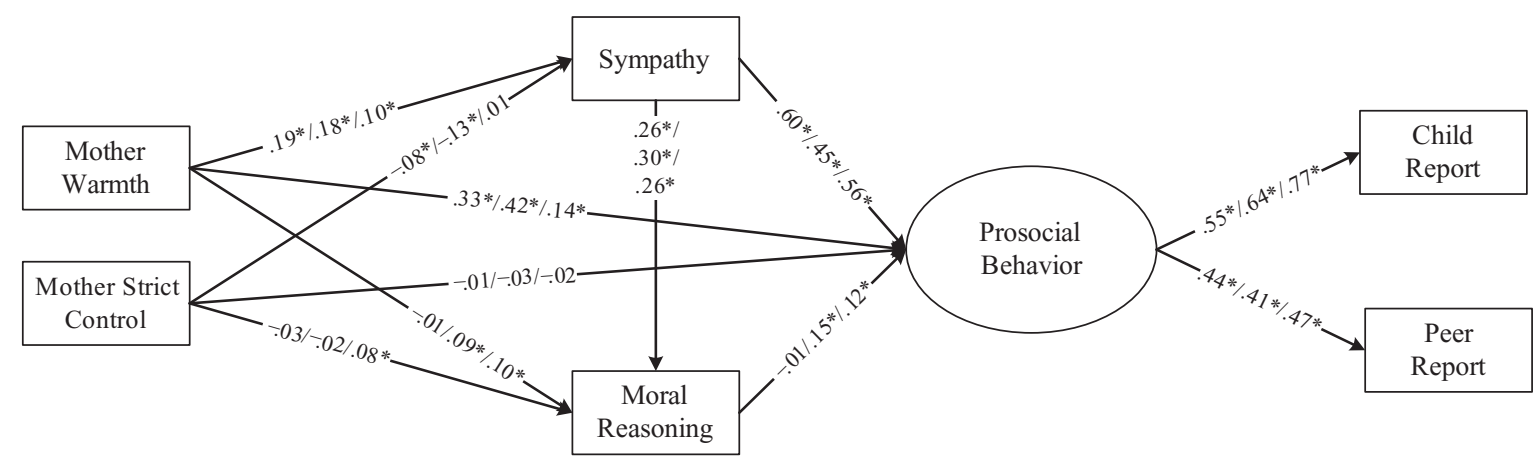

1b. Father warmth and strict control.

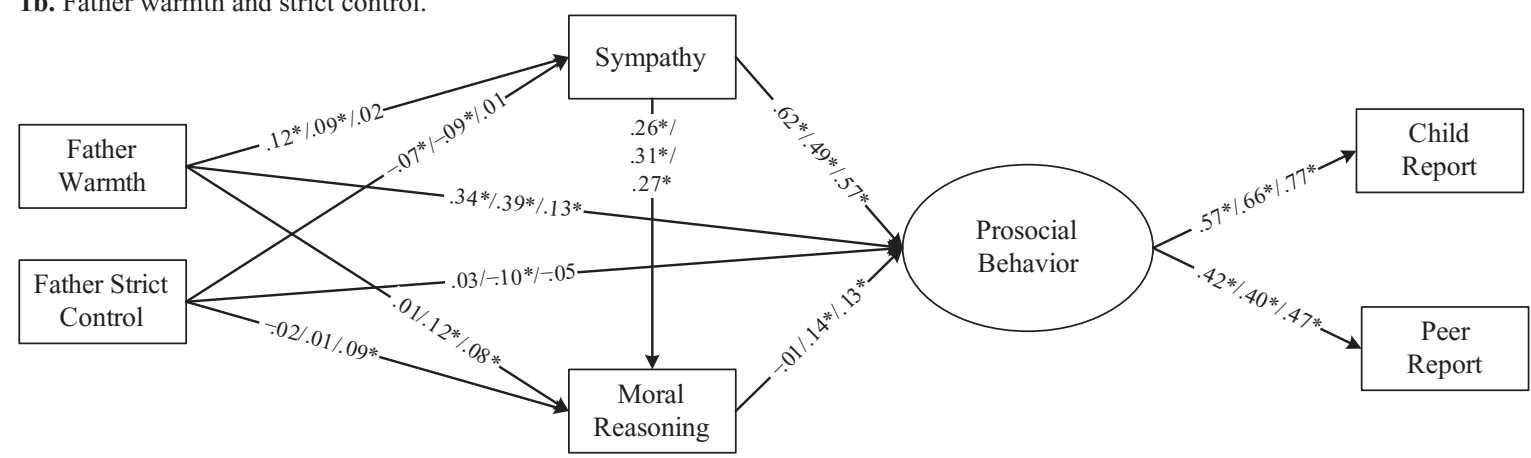

Figure I. Within wave structural equation model for (a) mother and (b) father warmth and strict control (Wave I/Wave 2/Wave 3).

Note: ${ }^{*} p<.05$.

category grouping variable was created in which boys and girls within each age group were assigned to a different category. A fully unconstrained model, in which each model parameter was allowed to vary across the groups, was then compared to a constrained model in which the parameters for the primary paths of interest were held constant across the groups. A $\Delta \chi^{2}$ test was used to compare the fit of the constrained models relative to the unconstrained models.

Bidirectional effect models (separately for mothers and fathers) were tested in which the causal ordering of the variables was reversed. Specifically, paths were included from Wave 1 prosocial behaviors to Wave 2 prosocial moral reasoning and sympathy, and from each of these variables to Wave 3 warmth and strict control. Wave 1 warmth, strict control, prosocial moral reasoning, and sympathy were used as controls for their corresponding Waves 2 and 3 variables.

\section{Within wave structural equation models}

All three models for mothers' warmth and strict control (Wave 1: $\chi^{2}(4)=8.28, p=.08, \mathrm{CFI}=.99, \mathrm{RMSEA}=.04, \mathrm{SRMR}=.02$; Wave $2: \chi^{2}(4)=12.77, p=.01, \mathrm{CFI}=.98, \mathrm{RMSEA}=.06, \mathrm{SRMR}$ $=.02$; Wave $3: \chi^{2}(4)=5.39, p=.25, \mathrm{CFI}=.99$, RMSEA $=.02$, SRMR $=.01$ ) and fathers' warmth and strict control (Wave $1: \chi^{2}(4)$ $=14.55, p<.01, \mathrm{CFI}=.97$, RMSEA $=.06$, SRMR $=.02$; Wave 2 : $\chi^{2}(4)=9.65, p=.05, \mathrm{CFI}=.98, \mathrm{RMSEA}=.04, \mathrm{SRMR}=.02$; Wave $3: \chi^{2}(4)=5.31, p=.26, \mathrm{CFI}=.99$, RMSEA $=.02$, SRMR $=.01)$ fit the data well. Although not depicted in the figures, there were modest significant effects of SES on Wave 1 and 3 prosocial moral reasoning, $\beta \mathrm{s}=-.11,-.08$, respectively, $p \mathrm{~s}<.05$, Wave 1 and 2 mothers' warmth, $\beta \mathrm{s}=-.18,-.09$, respectively, $p \mathrm{~s}<.05$, Wave 1 fathers' warmth, $\beta=-.12, p<.05$, and Wave 2 fathers' strict control, $\beta=-.10, p<.05$. SES was thus used as a covariate in all subsequent analyses.

Standardized path coefficients for each model are shown in Figures 1a (mothers' warmth and strict control) and 1b (fathers' warmth and strict control). Figure 1a shows a relatively consistent pattern of relations across the three waves such that mothers' warmth was positively related to sympathy and prosocial moral reasoning, and prosocial behaviors. In contrast, mothers' strict control was negatively related to sympathy at Waves 1 and 2, and positively related to prosocial moral reasoning at Wave 3. Furthermore, sympathy was positively related to prosocial moral reasoning and prosocial behaviors, and prosocial moral reasoning was related positively to prosocial behaviors at Waves 2 and 3 . The general pattern of relations for fathers' warmth and strict control was similar to that of the mothers' models. However, fathers' strict control was additionally related negatively to prosocial behaviors at Wave 2 .

\section{Longitudinal structural equation models}

The mothers' warmth and strict control, $\chi^{2}(18)=50.12, p<.01$, $\mathrm{CFI}=.97$, RMSEA $=.05, \mathrm{SRMR}=.03$, and fathers' warmth and strict control, $\chi^{2}(18)=63.45, p<.01, \mathrm{CFI}=.96, \mathrm{RMSEA}=.06$, $\mathrm{SRMR}=.04$, models fit the data well. SES was negatively associated with prosocial moral reasoning at Wave 1 for both models, $\beta \mathrm{s}=-.15, p \mathrm{~s}<.01$. SES was retained in the models but is not depicted in the figures. 


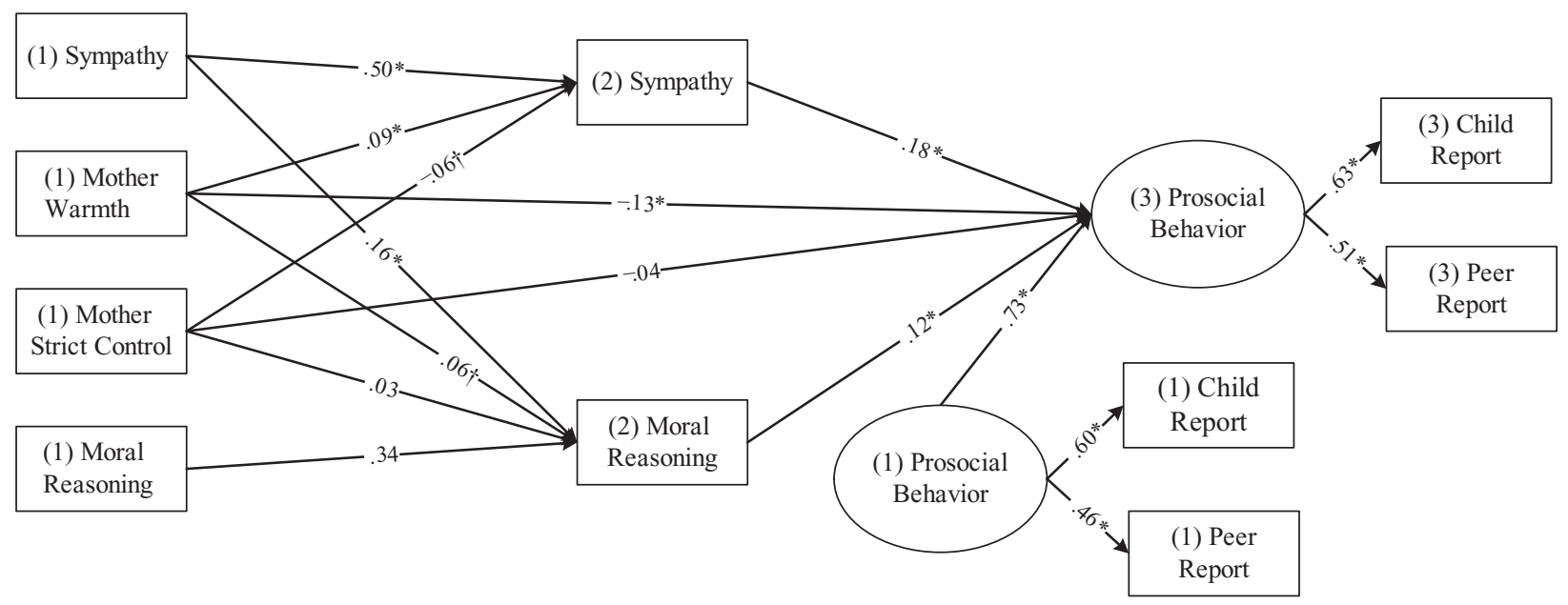

Figure 2. Longitudinal structural equation model for mothers' warmth and strict control. Note: $*_{p}<.05 ;{ }^{\dagger} p<10$.

Standardized path coefficients for mother model are shown in Figure 2 (mother warmth and strict control). Figure 2 shows that Wave 1 maternal warmth was positively associated with Wave 2 sympathy, and marginally positively associated with Wave 2 prosocial moral reasoning. Wave 1 maternal warmth was negatively related to Wave 3 prosocial behaviors. In contrast, Wave 1 mothers' strict control was marginally negatively associated with Wave 2 sympathy. Furthermore, Wave 2 sympathy and Wave 2 prosocial moral reasoning were linked positively to Wave 3 prosocial behaviors. Wave 1 sympathy was related positively to both Wave 2 prosocial moral reasoning and Wave 2 sympathy. Wave 1 prosocial moral reasoning was positively related to Wave 2 prosocial moral reasoning. Wave 1 prosocial behavior was linked positively to Wave 3 prosocial behavior. There were no other significant relations.

For fathers (model not depicted), Wave 2 sympathy was related positively to Wave 3 prosocial behaviors. Wave 1 sympathy was linked positively to Wave 2 sympathy and Wave 2 prosocial moral reasoning. Wave 1 prosocial moral reasoning was related to Wave 2 prosocial moral reasoning and Wave 2 prosocial behaviors were related to Wave 3 prosocial behaviors. There were no other significant relations. Multiple group analyses showed that age group and gender did not moderate the mothers' warmth and strict control model, $\Delta \chi^{2}(36)=50.42$, or the fathers' warmth and strict control model, $\Delta \chi^{2}(36)=29.68$.

\section{Bidirectional effects models}

The mothers' bidirectional model fit the data well, $\chi^{2}(19)=43.16$, $p=.001$, CFI $=.97$, RMSEA $=.04$, SRMR $=.02$. Wave 1 prosocial behavior was positively related to Wave 2 prosocial moral reasoning, $\beta=.21, p<.05$, and sympathy, $\beta=.33, p<$ .05 , and Wave 3 mothers' warmth, $\beta=.17, p<.05$, but was not significantly related to Wave 3 mothers' strict control, $\beta=-.09, p>$ .05 . Wave 1 prosocial moral reasoning was not significantly linked to Wave 2 sympathy, $\beta=.03, p>.05$;. Wave 2 prosocial moral reasoning was not significantly related to Wave 3 mothers' warmth, $\beta=-.13, p>.05$, but was positively related to Wave 3 mothers' strict control, $\beta=.10, p<.05$. Wave 2 sympathy was not significantly related to Wave 3 mothers' strict control, $\beta=.01, p<.05$, or warmth $\beta=-.02, p>.05$.
The fathers' warmth and strict control bidirectional model also fit the data well, $\chi^{2}(19)=53.89, p<.001$, CFI $=.95$, RMSEA $=$ $.05, \mathrm{SRMR}=.03$. Wave 1 prosocial behavior was positively associated with Wave 2 prosocial moral reasoning, $\beta=.21, p<.05$, and sympathy, $\beta=.26, p<.05$, but was not significantly related to Wave 3 fathers' warmth, $\beta=.13, p>.05$, and strict control $\beta=$ $-.09, p>.05$. Wave 1 prosocial moral reasoning was not significantly related to Wave 2 sympathy, $\beta=.04, p>.05$, Wave 3 fathers' strict control, $\beta=.08, p>.05$, or Wave 3 fathers' warmth, $\beta=.01, p>.05$. Wave 2 sympathy was not significantly related to Wave 3 fathers' warmth or strict control, $\beta \mathrm{s}=-.02 \& .04$, respectively, $p \mathrm{~s}>.05$.

\section{Discussion}

Overall, there was longitudinal and concurrent evidence that parental (especially maternal) warmth, sympathy, and prosocial moral reasoning are unique predictors of adolescents' prosocial behaviors. In contrast, parental strict control was negatively and weakly linked to such traits and behaviors (when there were significant relations). Moreover, there was supportive longitudinal evidence that maternal (but not paternal) warmth was related to sympathy but not prosocial moral reasoning, which was in turn related to prosocial behaviors. The relations were generally the same across age groups and gender. Bidirectional relations tests suggest that prosocial behaviors in earlier adolescence also predicted maternal warmth and later adolescents' prosocial traits. The results extend our understanding of the links among parenting, individual level variables, and prosocial behaviors in early adolescents from Spain.

\section{Relations between parenting and prosocial traits and behaviors}

Parental warmth was consistently positively associated with sympathy, prosocial moral reasoning, and prosocial behaviors. Concurrently, these relations were demonstrated in both fathers' and mothers' warmth; longitudinally, however, mothers' warmth was more predictive than fathers' warmth. These findings add to the mounting evidence that supports social cognitive models of 
prosocial development that identify parenting and individual difference characteristics (sympathy and prosocial moral reasoning) as important predictors of prosocial behaviors. The differences in the pattern between paternal and maternal warmth are interesting given the few studies that have directly compared the effects of fathers versus mothers in prosocial development. However, overall, there is evidence that maternal variables appear to be more consistently related to children's prosocial behaviors than paternal variables (see e.g., Carlo, Roesch, \& Melby, 1998). Perhaps this is because mothers have more opportunities to develop secure attachments with their children, and attachment has been linked to prosocial tendencies (Eisenberg et al., 2006). Surprisingly, there was a negative relation between maternal warmth and prosocial behaviors in the longitudinal, but positive relations in the concurrent model. We are uncertain about the cause of this suppressor effect. The fact that maternal warmth predicted sympathy but not prosocial moral reasoning may be due to the shared emotionality dimension of the former two variables. Future research is needed to replicate these findings.

Both fathers' and mothers' strict control were relatively equally weakly and generally nonsignificantly linked to prosocial traits and behaviors, in both the concurrent and longitudinal models. Furthermore, when strict control was significantly associated, it was usually negative (with a couple of exceptions). These findings suggest that overly strict control sometimes mitigates prosocial development, though such effects do not last over time. Moreover, the pattern of findings yields evidence that parental warmth is a more reliable predictor of prosocial development than parental strict control. However, caution is needed in overinterpreting these findings because the reliability coefficients for strict control measures were relatively low. Moreover, the present measure of control does not disentangle several distinct types of control styles, such as psychological and behavioral control (Barber et al., 2005) - future research might yield evidence that some types of control are more strongly associated with prosocial development than others. Finally, it is also possible that the interactive effects of parenting styles with other variables will need to be examined (Carlo et al., 1998), and that it is important to distinguish between parental practices and styles (Darling \& Steinberg, 1993).

\section{Relations of prosocial traits to prosocial behaviors}

As expected, both sympathy and prosocial moral reasoning predicted prosocial behaviors, both in concurrent and longitudinal models, even after controlling for preexisting levels of these variables. These findings lend further support to cognitivedevelopmental models of prosocial development that emphasize social cognitions such as moral reasoning (Eisenberg, 1986; Kohlberg, 1969) and moral internalization models that emphasize moral emotions such as sympathy (Barnett, 1987; Hoffman, 2000). In recent years, there has been some debate regarding the importance of moral emotions versus moral cognitions (see Haidt, 2001), but these findings add to the mounting evidence that both processes are important processes in understanding prosocial and moral development. Moreover, the fact that both variables predicted prosocial behaviors longitudinally over and above preexisting levels of sympathy, prosocial moral reasoning, and prosocial behaviors suggest that both sympathy and prosocial moral reasoning can predict change in levels of prosocial behaviors. Thus, both sociocognitive and socioemotive processes might account for developmental changes in prosocial behaviors.

\section{Relations of early prosocial behaviors to later prosocial traits and parenting}

Analyses of bidirectional effects revealed supportive evidence that early prosocial behaviors promote later parenting and prosocial development. These findings are consistent with prior research that shows that prosociality is relatively stable across adolescence (see Eisenberg et al., 2006) and the assertion that such stability might be due to social feedback processes (Carlo \& Randall, 2001). Although biological processes undoubtedly partially account for stability in prosociality (Knafo \& Plomin, 2006), engagement in prosocial behaviors earlier in life seems to facilitate later prosocial development (see also research on early community involvement; Lawford et al., 2005). These findings imply that youth who frequently act prosocially might be prone to develop prosocial traits that might strengthen their moral sense of self (Hart \& Fegley, 1995). Moreover, the fact that earlier prosocial behaviors predicted later maternal (but not paternal) warmth is the first such evidence that suggests that engaging in prosocial behaviors has effects on later parenting. The findings are consistent with theorized bidirectional effect expectations (e.g., Bell, 1968) that highlight the role of adolescents' social behaviors on parenting behaviors. Future research is needed to confirm and further examine this finding.

\section{Limitations and conclusions}

There were several important limitations to the present investigation. First, the study primarily relied on self-report measures and further studies with multiple methods will be needed to reduce shared method variance and social desirability concerns. Second, the reliabilities of some of the measures were somewhat low. Although prior evidence on their psychometric properties have been reported in studies of Spanish adolescents, some item deletions of the measures were necessarily conducted. Furthermore, the low reliabilities may be due to the relatively restricted range of the scales (e.g., 3 -point scales). Third, although longitudinal studies are better suited to examine direction of effects than cross-sectional studies, the use of interventions and experimental manipulations can help to better discern causality (Cole \& Maxwell, 2003; Kraemer, Stice, Kazdin, Offord, \& Kupfer, 2001). And fourth, the present sample was a relatively homogenous middle-class sample of early adolescents; research is needed to examine the generalizability of the findings to more diverse samples and later aged youth. Despite these limitations, the findings yield overall supportive evidence for significant links of parental warmth, sympathy, and prosocial moral reasoning to youth prosocial behaviors.

The overall pattern of findings is consistent with closely related studies conducted in samples from the United States and Brazil (Carlo et al., 1996; Eisenberg et al., 2001). Although, like the United States and Brazil, Spain is a relatively industrialized society, Spain generally differs from those countries on individualism and masculinity. However, overall, the findings yield evidence on the generalizability of socialization models of prosocial development to adolescents from Spain. This is not to necessarily infer that cross-cultural group differences in prosocial development are not present. Indeed, other researchers have shown that there are cross-cultural differences in prosocial moral reasoning and prosocial behaviors (de Guzman, Carlo, \& Edwards, 2008; Eisenberg et al., 2001); however, the mechanisms of prosocial development in Spanish-speaking, early adolescents appear to be similar to those 
identified in research in the United States and Brazil. Given the implications of understanding prosocial development for global peace and cooperation, more international research on this topic is warranted.

\section{Funding}

This research received no specific grant from any funding agency in the public, commercial, or not-for-profit sectors.

\section{References}

Bandura, A. (1986). Social foundations of thought and action: A social cognitive theory. Englewood Cliffs, NJ: Prentice-Hall.

Barber, B.K., Stolz, H.E., \& Olsen, J.A. (2005). Parental support, psychological control, and behavioral control: Assessing relevance across time, culture, and method. Monographs of the Society for Research in Child Development, 70, 1-137.

Barnett, M.A. (1987). Empathy and related responses in children. In N. Eisenberg \& J. Strayer (Eds.), Empathy and its development (pp. 146-162). Cambridge: Cambridge University Press.

Baumrind, D. (1991). The influence of parenting style on adolescent competence and substance abuse. Journal of Early Adolescence, 11, 56-95.

Bell, R.Q. (1968). A reinterpretation of the direction of effects in studies of socialization. Psychological Review, 75, 81-95.

Bryant, B.K. (1982). An index of empathy for children and adolescents. Child Development, 53, 413-425.

Caprara, G.V., \& Pastorelli, C. (1993). Early emotional instability, prosocial behavior, and aggression: Some methodological aspects. European Journal of Personality, 7, 19-36.

Carlo, G. (2006). Care-based and altruistically-based morality. In M. Killen \& J.G. Smetana (Eds.), Handbook of moral development (pp. 551-579). Mahwah, NJ: Erlbaum.

Carlo, G., Eisenberg, N., \& Knight, G.P. (1992). An objective measure of adolescents' prosocial moral reasoning. Journal of Research on Adolescence, 2, 331-349.

Carlo, G., Hausmann, A., Christiansen, S., \& Randall, B.A. (2003). Sociocognitive and behavioral correlates of a measure of prosocial tendencies for adolescents. Journal of Early Adolescence, 23, $107-134$

Carlo, G., Koller, S.H., Eisenberg, N., Da Silva, M., \& Frohlich, C. (1996). A cross-national study on the relations among prosocial moral reasoning, gender role orientations, and prosocial behaviors. Developmental Psychology, 32, 231-240.

Carlo, G., McGinley, M., Roesch, S.C., \& Kaminski, J. (2008). Culture group, age, and gender measurement invariance in prosocial moral reasoning among adolescents from Brazil and the United States. Journal of Moral Education, 37, 485-502.

Carlo, G., \& Randall, B. (2001). Are all prosocial behaviors equal? A socioecological developmental conception of prosocial behavior. In F. Columbus (Ed.), Advances in psychology research (Vol. II, pp. 151-170). Huntington, NY: Nova Science Publishers.

Carlo, G., Roesch, S.C., \& Melby, J. (1998). The multiplicative relations of parenting and temperament to prosocial and antisocial behaviors in adolescence. Journal of Early Adolescence, 18, 266-290.

Centro de Investigaciones Sociológicas (CIS). (2004). Revista Española de Investigaciones Sociológicas. Madrid: Ministerio de la Presidencia.

Cole, D.A., \& Maxwell, S.E. (2003). Testing mediational models with longitudinal data: Questions and tips in the use of structural equation modeling. Journal of Abnormal Psychology, 112, 558-577.
Darling, N., \& Steinberg, L. (1993). Parenting style as context: An integrative model. Psychological Bulletin, 113, 487-496.

de Guzman, M.R.T., Carlo, G., \& Edwards, C.P. (2008). Prosocial behaviors in context: Examining the role of children's social companions. International Journal of Behavioral Development, $32,522-530$.

De Prada, M.A., Actis, W., \& Pereda, C. (2005). Inmigración y vivienda en España. Colectivo Ioé. Madrid: Ministerio de Trabajo y Asuntos Sociales, Subdirección General de Información Administrativa y Publicaciones.

De Wolff, M.S., \& van IJzendoorn, M.H. (1997). Sensitivity and attachment: A meta-analysis of parental antecedents of infant attachment. Child Development, 68, 571-591.

Dekovic, M., \& Janssens, J.M.A.M. (1992). Parents' child-rearing style and child's sociometric status. Developmental Psychology, 28, 925-932.

Del Barrio, V., Moreno, C., \& López, R. (2001). Evaluación de la agresión e inestabilidad emocional en niños españoles y su relación con la depresión. Clínica y Salud, 13, 33-50.

Eberly, M.B., \& Montemayor, R. (1998). Doing good deeds: An examination of adolescent prosocial behavior in the context of parent/adolescent relationships. Journal of Adolescent Research, $13,403-432$.

Eisenberg, N. (1986). Altruistic emotion, cognition and behavior. Hillsdale, NJ: Lawrence Erlbaum Associates.

Eisenberg, N., Fabes, R.A., \& Spinrad, T.L. (2006). Prosocial development. In W. Damon \& R.M. Lerner (Series Eds.) \& N. Eisenberg (Vol. Ed.), Handbook of child psychology, Vol. 3: Social, emotional, and personality development (6th ed., pp. 646-718). New York, NY: John Wiley.

Eisenberg, N., Guthrie, I.K., Murphy, B.C., Shepard, S.A., Cumberland, A., \& Carlo, G. (1999). Consistency and development of prosocial dispositions: A longitudinal study. Child Development, 70, 1360-1372.

Eisenberg, N., \& Miller, P.A. (1987). The relation of empathy to prosocial and related behaviors, Psychological Bulletin, 101, 91-119.

Eisenberg, N., \& Valiente, C. (2002). Parenting and children's prosocial and moral development. Handbook of parenting, Vol. 5: Practical issues in parenting (2nd ed.) (pp. 111-142). Mahwah, NJ: Lawrence Erlbaum Associates.

Eisenberg, N., Zhou, Q., \& Koller, S. (2001). Brazilian adolescents' prosocial moral judgment and behavior: Relations to sympathy, perspective taking, gender-role orientation, and demographic characteristics. Child Development, 72, 518-534.

Erikson, E.H. (1968). Identity: Youth and crisis. New York, NY: Norton.

Fernández-Berrocal, P., Salovey, P., Vera, A., Ramos, N., \& Extremera, N. (2001). Cultura, inteligencia emocional percibida y ajuste emocional: Un estudio preliminar. Revista Electrónica de Motivación y Emoción, 4, 8-9.

Haidt, J. (2001). The emotional dog and its rational tail: A social intuitionist approach to moral judgment. Psychological Review, 108, 814-834.

Hart, D., \& Fegley, S. (1995). Altruism and caring in adolescence: Relations to self understanding and social judgment. Child Development, 66, 1346-1359.

Hoffman, M.L. (2000). Empathy and moral development: Implications for caring and justice. Cambridge: Cambridge University Press.

Hofstede, G.H. (2001). Culture's consequences (2nd ed.). Thousand Oaks, CA: Sage. 
Hu, L., \& Bentler, P.M. (1999). Cutoff criteria for fit indices in covariance structure analysis: Conventional criteria versus new alternatives. Structural Equation Modeling: An Interdisciplinary Journal, 6, 1-55.

Ibáñez, F.J. (2005). Conducta prosocial: Procesos psicológicos y variables familiares implicadas (Doctoral thesis, University of Valencia, Spain).

Instituto Nacional de Estadistica (2008). Retrieved from http://www. ine.es/

Kohlberg, L. (1969). Stage and sequence: The cognitive-developmental approach to socialization. In D. Goslin (Ed.), Handbook of socialization theory and research, (pp. 485-546). Stokie, IL: Rand McNally.

Knafo, A., \& Plomin, R. (2006). Prosocial behavior from early to middle childhood: Genetic and environmental influences on stability and change. Developmental Psychology, 42, 771-786.

Kraemer, H.C., Stice, E., Kazdin, A., Offord, D., \& Kupfer, D. (2001). How do risk factors work together to produce an outcome? Mediators, moderators, independent, overlapping and pseudo risk factors. American Journal of Psychiatry, 158, 848-856.

Lawford, H., Pratt, M.W., Hunsberger, B., \& Pancer, S.M. (2005). Adolescent generativity: A longitudinal study of two possible contexts for learning concern for future generation. Journal of Research on Adolescence, 15, 261-273.

Maccoby, E.E., \& Martin, J.A. (1983). Socialization in the context of the family: Parent-child interaction. In E.M. Hetherington (Ed.), Handbook of child psychology: Vol. 4, Socialization, personality, and social development (pp. 1-101). New York, NY: Wiley.
Mestre, V., Frías, M.D., Samper, P., \& Tur, A. (2002). Adaptación y validación en población española del PROM: Una medida objetiva del razonamiento moral prosocial. Acción psicológica, 1, 221-232.

Mestre, V., Pérez Delgado, E., Frías, M.D., \& Samper, P. (1999). Instrumentos de evaluación de la empatía. In E. Pérez Delgado \& V. Mestre (Eds.), Psicología moral y crecimiento personal (pp. 181-190). Barcelona: Ariel.

Mestre, V., Samper, P., Nácher, M.J., Tur, A., \& Cortés, M.T. (2006). Psychological processes and family variables as prosocial behavior predictors in a sample of Spanish adolescents. Psychological Reports, 98, 30-36.

Pratt, M., Skoe, E., \& Arnold, M. (2004). Care reasoning development and family socialisation patterns in later adolescence: A longitudinal analysis. International Journal of Behavioral Development, 28, 139-147.

Rollins, B.C., \& Thomas, D.L. (1979). Parental support, power, and control techniques in the socialization of children. In W.R. Burr, R. Hill, F.I. Nye, \& I.L. Reiss (Eds.), Contemporary theories about the family: Vol. 1 (pp. 317-364). New York, NY: Free Press.

Samper, P. (1999). Variables familiares y formación en valores (Doctoral thesis, University of Valencia, Spain).

Samper, P., Cortés, M.T., Mestre, M.V., Nácher, M.J., \& Tur, A. (2006). Adaptación en población española del Child's Report of Parent Behavior Inventory. Psicothema, 18, 263-271.

Schaefer, E.S. (1965). Children's reports of parental behavior: An inventory. Child Development, 36, 413-424.

Staub, E. (1979). Positive social behavior and morality: Socialization and development (Vol. 2). New York, NY: Academic Press. 